\title{
Low-molecular-weight heparin prophylaxis is not associated with decreased incidence of venous thromboembolism in testicular germ cell tumor patients receiving chemotherapy
}

\author{
Nikola HAPAKOVA, Michal CHOVANEC, Katarina REJLEKOVA, Katarina KALAVSKA, Jana OBERTOVA, Patrik PALACKA, Valentina DE ANGELIS, \\ Zuzana SYCOVA-MILA, Jozef MARDIAK, Michal MEGO* \\ $2^{\text {nd }}$ Department of Oncology, Comenius University, Faculty of Medicine, National Cancer Institute, Bratislava, Slovakia \\ ${ }^{*}$ Correspondence: misomego@gmail.com
}

Received September 9, 2021 / Accepted November 12, 2021

\begin{abstract}
Venous thromboembolism (VTE), commonly occurring in patients with testicular germ cell tumors (GCTs), is associated with increased morbidity and mortality. Prophylactic anticoagulation has been shown to decrease the risk of VTE in patients with malignancies. The objective was to evaluate the effect of low-molecular-weight heparin (LMWH) prophylaxis on the incidence of VTE and outcome in patients with GCT treated with first-line chemotherapy. In this retrospective study, 353 chemotherapy-naive GCT patients were treated with first-line chemotherapy at the National Cancer Institute, Bratislava, Slovakia (2000-2017). Median follow-up was 71 months. VTE was defined as any venous thrombosis or pulmonary embolism, confirmed by imaging, occurring during first-line chemotherapy. Exclusion criteria were LMWH use before starting chemotherapy and VTE on initial staging. We observed 14 (4.0\%) VTE events. No visceral thromboses were observed. The difference in VTE incidence between patients with and without prophylaxis was not statistically significant $(5.8 \%$ vs. $3.2 \%, p=0.37)$. We observed a trend toward longer overall survival in patients without prophylaxis (hazard ratio $=$ $0.61,95 \%$ confidence interval $=0.32-1.13, \mathrm{p}=0.08$ ). Patients with extragonadal GCT receiving VTE prophylaxis had significantly shorter survival (hazard ratio $=0.29,95 \%$ confidence interval $=0.08-1.12, \mathrm{p}=0.04$ ). This effect was most likely driven by a higher incidence of treatment-related deaths in patients with extragonadal GCT receiving LMWH ( $\mathrm{p}=0.06)$. LMWH prophylaxis was not associated with decreased VTE incidence. Moreover, there was a higher incidence of treatment-related deaths in patients with extragonadal tumor location. Low-molecular-weight heparin prophylaxis during hospitalization should not be used routinely in patients with testicular germ cell tumors receiving chemotherapy.
\end{abstract}

Key words: testicular germ cell tumors, venous thromboembolism, low-molecular-weight heparin, prophylaxis, chemotherapy

Testicular germ cell tumors (GCTs) represent one of the most common solid neoplasms in young males, and the incidence has been steadily rising in recent decades $[1,2]$. Cisplatin-based chemotherapy with or without resection of the residual mass is highly effective in the treatment of GCTs with a five-year survival rate of more than $95 \%$ [3]. As a result, the number of GCT survivors with a long-life expectancy is rising. Therefore, maintaining patients' quality of life and minimizing treatment-related morbidity and mortality has gained significant interest in recent years.

Venous thromboembolism (VTE) affects approximately $10 \%$ of cancer patients [4]. The multifactorial pathophysiology is related to the type of tumor, anatomic location, patient comorbidities, type of treatment, etc. [5] Compared to patients with different types of malignancy, GCT patients have a higher incidence of VTE events [6].
VTE is associated with increased morbidity and mortality in patients with cancer. Levitan et al. found more than a threefold higher risk of recurrent VTE and death in patients with cancer compared to patients with VTE without cancer diagnosis [7].

Few studies assessed the incidence of VTE in GCT patients, and the results vary widely. Honecker et al. observed a 9\% VTE incidence in patients before starting chemotherapy, while there was only a $2 \%$ incidence of VTE during first-line chemotherapy [8]. In a different study, Piketty et al. found a $14 \%$ incidence of VTE during first-line chemotherapy and a $5 \%$ incidence of VTE after chemotherapy [6].

Several groups have focused on the identification of risk factors for VTE events in GCT patients [6, 9-12]. Weijl et al. observed an increased risk of VTE in patients with liver metastases (odds ratio $(\mathrm{OR})=4.9)$ [10]. Piketty et al. identi- 
fied body surface area $>1.9 \mathrm{~m}^{2}$ (relative risk $(\mathrm{RR})=5,95 \%$ confidence interval (CI) 1.8-13.9) and elevated serum lactate dehydrogenase ( $\mathrm{RR}=6.4,95 \% \mathrm{CI} 2.3-18.2$ ) as independent risk factors. In their study, patients without any risk factors had a $4 \%$ probability of having VTE, while patients with at least 1 risk factor had a 26\% probability of having VTE [6].

Prophylactic anticoagulation has been shown to decrease the risk of symptomatic VTE in cancer patients $(\mathrm{RR}=0.56$, 95\% CI 0.47-0.68) [13]. Gizzi et al. studied the incidence of thromboembolic events in GCT patients treated with firstline chemotherapy and observed a lower incidence of thromboembolic events in patients receiving thromboprophylaxis than in patients without prophylaxis [12]. However, the small number of patients in each subgroup of this study makes the interpretation of the results difficult, and a larger study is needed to elucidate the relationship between thromboprophylaxis and the incidence of VTE in patients with GCT undergoing cisplatin-based chemotherapy.

The aim of this retrospective study was to evaluate the effect of low-molecular-weight heparin (LMWH) prophylaxis on the incidence of VTE events and outcomes in patients with germ cell tumors treated with first-line chemotherapy.

\section{Patients and methods}

Study patients. This retrospective study was conducted using the National Cancer Institute medical records database. The study was approved by the Institutional Review Board, and a waiver of the consent form for the collection, analysis, and publication of the retrospectively obtained and anonymized data for this noninterventional study was granted. We confirm that all methods were performed in accordance with the relevant guidelines and regulations. Patients diagnosed with GCT treated with first-line/adjuvant chemotherapy at the National Cancer Institute, Bratislava, Slovakia, from January 2000 to December 2017 were eligible. Exclusion criteria were concurrent malignancy other than nonmelanoma skin cancer in the previous 5 years, previous chemotherapy, VTE diagnosed on the initial staging exam, and anticoagulation therapy (therapeutic or prophylactic) started before the initiation of first-line chemotherapy.

Definition of VTE event. VTE events were defined as any venous thrombosis or pulmonary embolism occurring between Day 1 of the first cycle of first-line chemotherapy and Day 21 of the last cycle of first-line chemotherapy. Cases of superficial phlebitis were not classified as events. Every VTE event had to be confirmed by imaging studies, either Doppler ultrasonography or a CT scan. Depending on the patients' presenting symptoms, the events were divided into symptomatic and incidental if discovered on imaging performed for a different purpose. The Khorana score was calculated as described previously [14].

Baseline data. During the initial staging, patients had a CT scan of the chest, abdomen, and pelvis. Baseline data regarding age, primary tumor location, tumor histology,
TNM stage, International Germ Cell Cancer Collaborative Group (IGCCCG) risk class, and first-line chemotherapy regimen were recorded. Blood coagulation tests were not routinely performed during the initial screening.

VTE prophylaxis. LMWH prophylaxis was not routinely prescribed before January 2010 during hospitalization. At our institution, all GCT patients are hospitalized during chemotherapy. In December 2007, the American Society of Clinical Oncology released clinical practice guidelines recommending prophylactic anticoagulation for hospitalized patients receiving chemotherapy [15]. Therefore, starting in January 2010, we progressively implemented prophylactic anticoagulation with LMWH (nadroparin $0.4 \mathrm{ml}$ or equivalent). However, not all physicians integrated this guideline into their practice, and LMWH prophylaxis was prescribed at the individual physician's discretion.

Statistical analysis. We performed a retrospective review of patients' medical records. All thromboses or pulmonary embolisms, confirmed by imaging modality, were classified as events. Fisher's exact test was used for statistical analysis to compare VTE events between groups with and without prophylaxis.

The primary outcome was the overall incidence of VTE events occurring during first-line chemotherapy. Secondary outcomes were incidences of VTE events in various subgroups and overall survival.

Time to VTE was calculated from the start date of chemotherapy to the date of VTE diagnosis. The log-rank test was used to compare the differences between time to VTE between patients with and without prophylaxis.

Median follow-up was calculated as the median time of observation of the study patients. Overall survival was calculated from the start date of chemotherapy to the date of the last follow-up or death of the patient. The Kaplan-Meier method was used to estimate overall survival. The log-rank test was used to compare differences in survival between patients with and without prophylaxis. All calculations were performed using NCSS 2019 statistical software [16].

\section{Results}

Patient characteristics. Our cohort included 353 patients (Figure 1). The patient characteristics are summarized in Table 1. The median age of patients at the time of enrollment was 32 years (ranging from 17 to 63 years). All patients received platinum-based chemotherapy.

VTE prophylaxis. LMWH prophylaxis was administered to 104 patients (29.5\%) for the duration of hospitalization for chemotherapy (Figure 1). The majority of patients (74.3\%) receiving LMWH prophylaxis after January 2010 were stage II.B or higher. Heparin assays were not routinely performed to confirm the levels.

VTE events. In our study population, most VTE events occurred even before starting chemotherapy. These patients were excluded from the study (Figure 1). 
During the study period, we observed 14 (4.0\%) VTE events. Deep vein thrombosis was observed in 13 patients (3.7\%), and one patient $(0.3 \%)$ had a pulmonary embolism. No visceral thromboses were observed (Supplementary Table S1). One event (7.1\%) was fatal. In patients without prophylaxis, we documented eight events (3.2\%), while six events (5.8\%) were documented in patients receiving $\mathrm{LMWH}$ prophylaxis $(\mathrm{p}=0.37)$. The data are summarized in Table 2 . The median age of patients with and without VTE was 34 years vs. 31 years, $\mathrm{p}=0.24$.

In patients who experienced VTE, the median time to VTE was 28.5 days (15-83 days) in patients without prophylaxis and 53.5 days (1-92 days) in patients with prophylaxis (hazard ratio $(\mathrm{HR})=0.53,95 \%$ CI $0.17-1.7, \mathrm{p}=0.24)$.

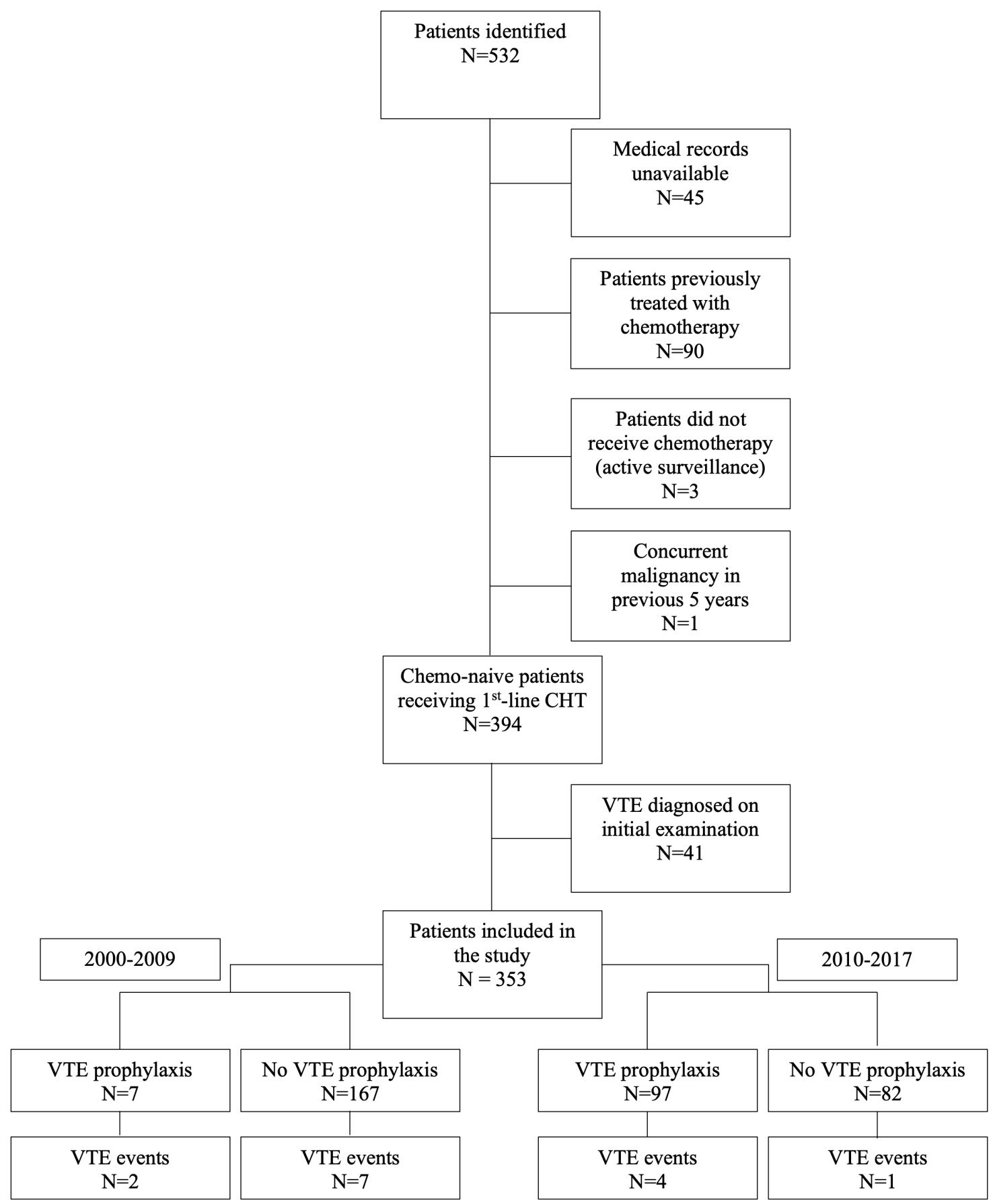

Figure 1 Flow diagram. Medical records search for patients with GCT treated between 2000 and 2017 
The incidence of VTE in patients without prophylaxis before 2010 was similar to the incidence of VTE in the subgroup of patients with prophylaxis after 2010, as well as in the subgroup analysis based on the IGCCCG risk group (Supplementary Table S2).

Table 1. Patient characteristics.

\begin{tabular}{|c|c|c|}
\hline & $\mathrm{N}$ & $\%$ \\
\hline All & 353 & 100 \\
\hline \multicolumn{3}{|l|}{ Histology } \\
\hline Seminoma & 79 & 22.4 \\
\hline NSGCT & 268 & 75.9 \\
\hline Unknown & 6 & 1.7 \\
\hline \multicolumn{3}{|l|}{ Primary tumor } \\
\hline Gonadal & 318 & 90.1 \\
\hline Extragonadal & 35 & 9.9 \\
\hline Retroperitoneum & 22 & 6.2 \\
\hline Mediastinum & 10 & 2.8 \\
\hline Brain & 2 & 0.6 \\
\hline Unknown & 1 & 0.3 \\
\hline \multicolumn{3}{|l|}{ Stage } \\
\hline I.A/B & 38 & 10.8 \\
\hline I.S & 22 & 6.2 \\
\hline II.A & 30 & 8.5 \\
\hline II.B & 47 & 13.3 \\
\hline II.C & 44 & 12.5 \\
\hline III.A & 43 & 12.2 \\
\hline III.B & 42 & 11.9 \\
\hline III.C & 87 & 24.6 \\
\hline \multicolumn{3}{|l|}{ IGCCCG risk group } \\
\hline Stage IA/B & 38 & 10.8 \\
\hline Good & 192 & 54.4 \\
\hline Intermediate & 46 & 13.0 \\
\hline Poor & 77 & 21.8 \\
\hline \multicolumn{3}{|l|}{ Treatment regimen } \\
\hline BEP & 250 & 70.8 \\
\hline Other & 103 & 29.2 \\
\hline \multicolumn{3}{|l|}{ Follow-up status } \\
\hline Alive & 300 & 84.99 \\
\hline Exitus & 51 & 14.45 \\
\hline Unknown & 2 & 0.57 \\
\hline \multicolumn{3}{|l|}{ Khorana score } \\
\hline 1 & 231 & 65.44 \\
\hline 2 & 73 & 20.68 \\
\hline 3 & 44 & 12.46 \\
\hline 4 & 5 & 1.42 \\
\hline \multicolumn{3}{|c|}{ Size of retroperitoneal lymph nodes (N-stage) } \\
\hline Normal (N0) & 84 & 23.80 \\
\hline$<2 \mathrm{~cm}(\mathrm{~N} 1)$ & 47 & 13.31 \\
\hline$>2 \mathrm{~cm}<5 \mathrm{~cm}(\mathrm{~N} 2)$ & 75 & 21.25 \\
\hline$>5 \mathrm{~cm}(\mathrm{~N} 3)$ & 136 & 38.53 \\
\hline Unknown & 11 & 3.12 \\
\hline
\end{tabular}

Association between VTE prophylaxis and patient/ tumor characteristics. There were no statistically significant differences in VTE incidence between patients with and without prophylaxis based on primary tumor location or histology.

Patients with intermediate or poor-risk were more likely to suffer VTE events than patients with good risk according to the IGCCCG classification (7.3\% vs. $2.2 \%, \mathrm{p}=0.02)$. However, VTE incidence did not differ significantly in patients with and without prophylaxis for any of the risk groups. Similarly, the Khorana score and/or size of retroperitoneal lymph nodes had no impact on the effect of prophylactic anticoagulation (Table 2).

Out of the fourteen patients suffering VTE events, 8 patients received bleomycin, etoposide, and cisplatin (BEP); 3 patients had a dose-dense regimen [17]; two patients received paclitaxel, bleomycin, etoposide, and cisplatin; and one patient was treated with etoposide and cisplatin.

Association between overall survival and prophylactic anticoagulation. The median follow-up of all patients was 71 months (0-224 months). The median follow-up of living patients was 122 months (1-224 months). There were 51

Table 2. VTE events.

\begin{tabular}{|c|c|c|c|c|c|}
\hline & \multicolumn{2}{|c|}{ No prophylaxis } & \multicolumn{2}{|c|}{$\begin{array}{c}\mathrm{VTE} \\
\text { prophylaxis }\end{array}$} & \multirow[t]{2}{*}{ p-value } \\
\hline & $\mathrm{N}$ & $\%$ & $\mathbf{N}$ & $\%$ & \\
\hline All VTE events & $8 / 249$ & 3.2 & $6 / 104$ & 5.8 & 0.3681 \\
\hline Incidental events & $2 / 8$ & 25.0 & $4 / 6$ & 66.7 & \multirow{2}{*}{0.2774} \\
\hline Symptomatic events & $6 / 8$ & 75.0 & $2 / 6$ & 33.3 & \\
\hline \multicolumn{6}{|l|}{ Histology } \\
\hline Seminoma & $1 / 45$ & 2.2 & $1 / 34$ & 2.9 & 1.0000 \\
\hline NSGCT & $7 / 197$ & 3.4 & $5 / 64$ & 7.8 & 0.1653 \\
\hline \multicolumn{6}{|l|}{ Primary tumor location } \\
\hline Gonadal & $8 / 228$ & 3.5 & $4 / 90$ & 4.4 & 0.7461 \\
\hline Extragonadal & $0 / 21$ & 0.0 & $2 / 14$ & 14.3 & 0.1529 \\
\hline \multicolumn{6}{|l|}{ IGCCCG risk group } \\
\hline Stage IA/B & $0 / 34$ & 0.0 & $0 / 4$ & 0.0 & 1.0000 \\
\hline Good & $4 / 135$ & 3.0 & $1 / 57$ & 1.8 & 1.0000 \\
\hline Intermediate & $1 / 31$ & 3.2 & $2 / 15$ & 13.3 & 0.2444 \\
\hline Poor & $3 / 49$ & 6.1 & $3 / 28$ & 10.7 & 0.6622 \\
\hline \multicolumn{6}{|l|}{ Chemotherapy regimen } \\
\hline BEP & $6 / 183$ & 3.3 & $2 / 67$ & 3.0 & 1.0000 \\
\hline Other & $2 / 66$ & 3.0 & $4 / 37$ & 10.8 & 0.1844 \\
\hline \multicolumn{6}{|l|}{ Khorana score } \\
\hline 1 & $6 / 171$ & 3.5 & $1 / 60$ & 1.7 & 0.6800 \\
\hline 2 & $2 / 52$ & 3.8 & $1 / 21$ & 6.4 & 1.0000 \\
\hline 3 & $0 / 22$ & 0.0 & $4 / 22$ & 1.8 & 0.1078 \\
\hline 4 & $0 / 4$ & 0.0 & $0 / 1$ & 0.0 & 1.0000 \\
\hline \multicolumn{6}{|c|}{ Size of retroperitoneal lymph nodes (N-stage) } \\
\hline Normal (N0) & $1 / 70$ & 1.4 & $1 / 12$ & 8.3 & 0.2871 \\
\hline$<2 \mathrm{~cm}(\mathrm{~N} 1)$ & $2 / 38$ & 5.3 & $1 / 6$ & 16.7 & 0.3907 \\
\hline$>2 \mathrm{~cm}<5 \mathrm{~cm}(\mathrm{~N} 2)$ & $1 / 43$ & 2.3 & $0 / 31$ & 0.0 & 1.0000 \\
\hline$>5 \mathrm{~cm}(\mathrm{~N} 3)$ & $3 / 85$ & 3.5 & $4 / 44$ & 9.1 & 0.2426 \\
\hline
\end{tabular}


deaths $(14.45 \%)$ in our study population. The 2- and 5-year overall survival rates of the study group were $87.99 \%$ (95\% CI $84.49-91.49 \%$ ) and $84.27 \%$ (95\% CI $80.22-88.31 \%$ ), respectively. There was no difference in overall survival in patients with or without prophylaxis (HR=0.61, 95\% CI $0.32-1.13$; $\mathrm{p}=0.0784$; Figure 2). The results are summarized in Table 3. Patients with extragonadal GCT and patients with NSGCT histology receiving VTE prophylaxis had significantly shorter survival than patients without prophylaxis $(\mathrm{HR}=0.29$, 95\% CI $0.08-1.12$; $\mathrm{p}=0.0373, \mathrm{HR}=0.50,95 \%$ CI $0.25-0.99$; $\mathrm{p}=0.0179$, respectively; Figures $3 \mathrm{~A}, 3 \mathrm{~B})$. We also observed a trend toward shorter overall survival in patients receiving prophylaxis with chemotherapy regimens other than BEP $(\mathrm{HR}=0.50,95 \%$ CI $0.22-1.12 ; \mathrm{p}=0.0614)$.

We analyzed the incidence of treatment-related deaths (TRDs) in patients with primary extragonadal tumors and NSGCT histology based on LMWH prophylaxis (Supplementary Table S3). TRD was defined as a death during first-line chemotherapy. Patients with extragonadal tumors receiving LMWH prophylaxis had a higher incidence of TRD than patients without prophylaxis $(21.4 \%$ vs. $0.0 \%, \mathrm{p}=0.0556)$. Patients with NSGCT histology on LMWH prophylaxis also had a higher incidence of TRD than patients without prophylaxis $(10.9 \%$ vs. $3.9 \%, \mathrm{p}=0.0552)$. In the subgroup analysis of patients with NSGCT histology, we found that this trend was driven by TRD in patients with primary extragonadal tumors.

Incidence of major bleeding during VTE prophylaxis. Thirteen patients in our cohort suffered major bleeding (grades $3-5)$. There were 7 patients $(2.8 \%)$ who received no prophylaxis, and 6 patients $(5.8 \%)$ received LMWH prophylaxis $(\mathrm{p}=0.22)$.

\section{Discussion}

In the present study, we examined the relationship between prophylactic anticoagulation during chemotherapy and the incidence of VTE events as well as the association between prophylactic anticoagulation and the overall survival of GCT patients treated with first-line chemotherapy. To assess the effect of prophylactic anticoagulation on the incidence of VTE events, we included only events occurring during firstline chemotherapy when patients were also receiving LMWH prophylaxis.

We have observed that most VTE events occur even before the initiation of chemotherapy. Besides systemic therapy, there are at least two important factors that increase the risk of VTE in GCT patients. First, the presence of a tumor, by itself, increases the risk of thrombus formation. This is because most cancer cells have the ability to activate the coagulation system [18]. Secondly, GCTs metastasize to retroperitoneal lymph nodes (RPLN), frequently reaching a considerable size and thus causing mechanical obstruction of abdominal and pelvic veins [19]. Large RPLN size has been identified as an independent VTE risk factor in previous studies $[9,12,20]$.

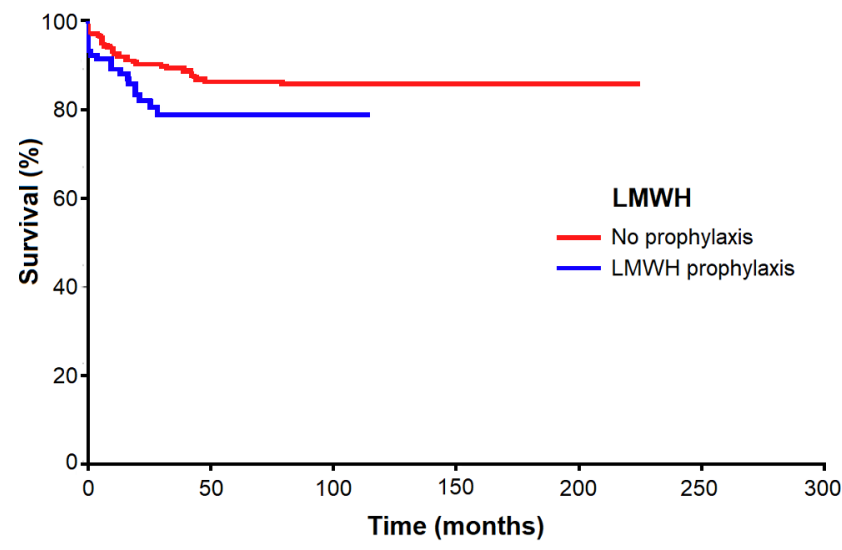

Figure 2. Kaplan-Meier estimates of probabilities of overall survival according to VTE prophylaxis in testicular germ cell tumor patients $(\mathrm{n}=353), \mathrm{HR}=0.61,95 \%$ CI $0.32-1.13 ; \mathrm{p}=0.0784$
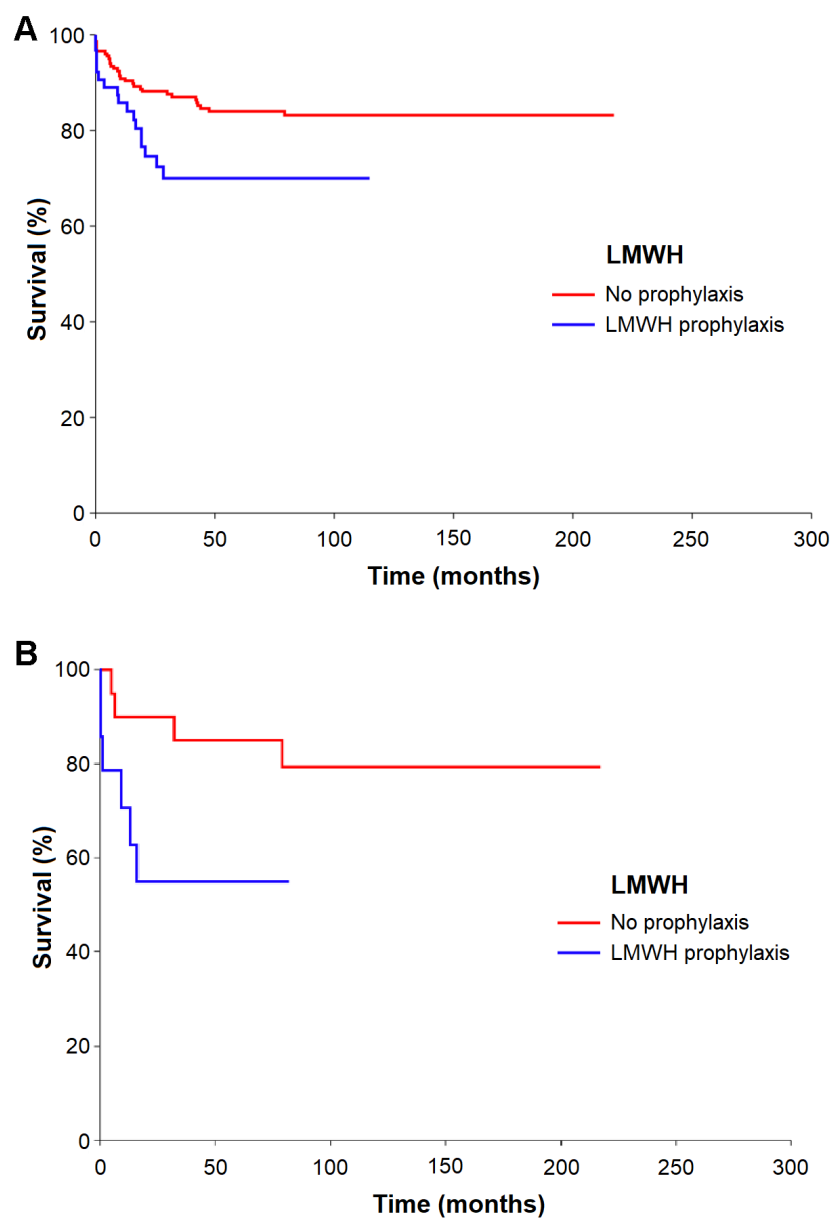

Figure 3. A) Kaplan-Meier estimates of probabilities of overall survival according to VTE prophylaxis in non-seminomatous germ cell tumor patients $(\mathrm{n}=268), \mathrm{HR}=0.29,95 \%$ CI 0.08-1.12; $\mathrm{p}=0.0373$; B) Kaplan-Meier estimates of probabilities of overall survival according to VTE prophylaxis in extragonadal germ cell tumor patients $(n=35), \mathrm{HR}=0.50,95 \% \mathrm{CI}$ $0.25-0.99 ; \mathrm{p}=0.0179$ 
Table 3. Overall survival.

\begin{tabular}{|c|c|c|c|c|c|c|}
\hline & VTE prophylaxis & $\mathbf{N}$ & HR & Lower 95\% CI & Upper $95 \%$ CI & p-value \\
\hline All patients & $0 / 1$ & $249 / 104$ & 0.61 & 0.32 & 1.13 & 0.0784 \\
\hline \multicolumn{7}{|l|}{ IGCCCG risk group } \\
\hline Stage IA/B & $0 / 1$ & $34 / 4$ & 0.00 & 0.00 & 0.00 & 0.6532 \\
\hline Good & $0 / 1$ & $135 / 57$ & 1.09 & 0.12 & 9.99 & 0.9425 \\
\hline Intermediate & $0 / 1$ & $31 / 15$ & 0.72 & 0.06 & 9.36 & 0.7836 \\
\hline Poor & $0 / 1$ & $49 / 28$ & 0.69 & 0.36 & 1.33 & 0.2368 \\
\hline \multicolumn{7}{|l|}{ Chemotherapy regimen } \\
\hline BEP & $0 / 1$ & $183 / 67$ & 0.94 & 0.37 & 2.42 & 0.8975 \\
\hline Other & $0 / 1$ & $66 / 37$ & 0.5 & 0.22 & 1.12 & 0.0614 \\
\hline \multicolumn{7}{|l|}{ Tumor histology } \\
\hline Seminoma & $0 / 1$ & $45 / 34$ & 0.58 & 0.03 & 10.34 & 0.6988 \\
\hline NSGCT & $0 / 1$ & $204 / 64$ & 0.5 & 0.25 & 0.99 & 0.0179 \\
\hline \multicolumn{7}{|l|}{ Primary tumor location } \\
\hline Gonadal & $0 / 1$ & $228 / 90$ & 0.76 & 0.38 & 1.53 & 0.4178 \\
\hline Extragonadal & $0 / 1$ & $21 / 14$ & 0.29 & 0.08 & 1.12 & 0.0373 \\
\hline \multicolumn{7}{|l|}{ Khorana score } \\
\hline 1 & $0 / 1$ & $171 / 60$ & 0.83 & 0.25 & 2.76 & 0.7555 \\
\hline 2 & $0 / 1$ & $52 / 21$ & 0.71 & 0.23 & 2.23 & 0.5272 \\
\hline 3 & $0 / 1$ & $22 / 22$ & 0.69 & 0.26 & 1.83 & 0.4461 \\
\hline 4 & $0 / 1$ & $4 / 1$ & 0.38 & 0.02 & 8.45 & 0.3508 \\
\hline \multicolumn{7}{|c|}{ Size of retroperitoneal lymph nodes (N-stage) } \\
\hline Normal (N0) & $0 / 1$ & $71 / 13$ & 0.67 & 0.12 & 3.94 & 0.6161 \\
\hline$<2 \mathrm{~cm}(\mathrm{~N} 1)$ & $0 / 1$ & $40 / 7$ & 0.54 & 0.03 & 8.24 & 0.5824 \\
\hline$>2 \mathrm{~cm}<5 \mathrm{~cm}(\mathrm{~N} 2)$ & $0 / 1$ & $44 / 31$ & 0.42 & 0.07 & 2.52 & 0.3179 \\
\hline$>5 \mathrm{~cm}(\mathrm{~N} 3)$ & $0 / 1$ & $88 / 48$ & 0.88 & 0.38 & 2.00 & 0.7475 \\
\hline
\end{tabular}

There was a $4 \%$ incidence of VTE events occurring during chemotherapy. The observed incidence of VTE events is in line with the incidences reported in the literature $[6,8,10$, $19,21,22]$. However, there is a wide variation in the reported incidences [23]. While the lowest reported incidence is $2 \%$, in a different study, there was an incidence of thromboembolic events of $23.7 \%$ [8, 22]. A significant part of this variation is probably caused by different inclusion criteria, such as including arterial events, including patients with VTE events before the start of chemotherapy, and events occurring several months after chemotherapy. The small number of patients in some studies may also contribute to this variability.

We observed no significant differences in VTE incidence between patients with and without LMWH prophylaxis. While there have been several studies assessing VTE incidence and identifying VTE risk factors in patients with GCT, most of them included only a small number of the study patients with LMWH prophylaxis. We did not observe a beneficial effect of prophylactic anticoagulation even in patients with recognized risk factors for VTE, including a high Khorana score and/or increased retroperitoneal lymph node size $[14,20]$.

Solari et al. compared the incidence of thromboembolic events in patients receiving limited and extended LMWH prophylaxis. Limited prophylaxis was administered only during hospitalization. Extended prophylaxis was administered daily from Day 1 of the first cycle to Day 21 of the last cycle of chemotherapy. They did not observe significant differences between these two groups. However, their study did not include a control group with no prophylaxis; therefore, the effect of LMWH prophylaxis cannot be assessed. Paradoxically, the incidence of thromboembolic events reported in their study (23.7\%) was much higher than in other studies [22]. However, arterial events were also included in their analysis. Gizzi et al. also compared the VTE incidence in patients with GCT with and without LMWH prophylaxis. In their study, prophylaxis was administered to a subgroup of patients with risk factors for VTE (elevated lactate dehydrogenase or high body surface area). They observed no statistically significant difference in VTE incidence between the two groups. However, neither the type of LMWH used nor the dosing of prophylaxis was mentioned [12].

Unexpectedly, there was a trend toward shorter overall survival in our patients who received LMWH prophylaxis. On further analysis, we found a significantly shorter overall survival in patients receiving LMWH prophylaxis with NSGCT histology or extragonadal tumor location.

A prospective study assessing the effect of prophylactic anticoagulation in patients with GCT receiving chemotherapy compared to no prophylaxis is lacking. However, the 
data available suggest that LMWH prophylaxis does not offer the expected benefits in terms of decreased incidence of VTE events in patients with GCT $[12,22]$. In contrast, our data suggest that administering LMWH prophylaxis might confer a higher risk for treatment-related deaths in patients with extragonadal tumors. Given the small number of patients with extragonadal tumors included in our study and selection bias, this result is only hypothesis-generating. Further research should focus on examining the possible association between LMWH and an increased incidence of TRDs. In October 2019, the American Society of Clinical Oncology published an updated guideline on the use of thromboprophylaxis in patients with cancer. According to this guideline, hospitalized patients with active malignancy without additional risk factors may be offered pharmacologic thromboprophylaxis. However, routine use of thromboprophylaxis in patients with cancer hospitalized solely for the administration of chemotherapy is no longer recommended [24].

To the best of our knowledge, this is the largest study evaluating the effect of LMWH prophylaxis on VTE incidence in patients with GCT receiving chemotherapy. Our study has several limitations. First, LMWH prophylaxis was not random, possibly causing selection bias. It is possible that patients at higher risk for VTE were given thromboprophylaxis more frequently, which could in turn obscure the effect of thromboprophylaxis. However, the incidence of VTE in patients without prophylaxis before 2010 was similar to the incidence of VTE in the subgroup of patients with prophylaxis after 2010, as well as in the subgroup analysis based on the IGCCCG risk group (Supplementary Table S1). This supports the conclusion of no beneficial effect of prophylaxis in patients with GCTs. Second, the study has a retrospective design. Some VTE events could have been missed as a result of incomplete medical records.

In conclusion, in this large retrospective analysis, we showed that LMWH prophylaxis was not associated with decreased VTE incidence. Moreover, there was a higher incidence of treatment-related deaths in patients with extragonadal tumor location. Taking into account these data, LMWH prophylaxis during hospitalization should not be used in patients with GCT receiving chemotherapy.

Take home message. LMWH prophylaxis in GCT patients hospitalized for chemotherapy was not associated with decreased VTE incidence and therefore should not be used routinely. Moreover, LMWH prophylaxis was associated with a higher incidence of treatment-related deaths in patients with extragonadal tumor location.

Acknowledgments: We would like to acknowledge Mrs. Daniela Slackova from the Population Registry of the Slovak Republic for help with updating the patient databases and Dr. Maria Reckova for discussions and critical input. We would like to acknowledge Dr. Daniela Světlovská for administration support. This work was supported by the VEGA Grant Agency of the Slovak Republic (VEGA 1/0043/18), the Slovak Research and Development Agency (grants
APVV-15-0086 and APVV-20-0158), and the Ministry of Health (MZ SR 2018/39-LFUK-13). The sponsors played no direct role in the study.

Supplementary information is available in the online version of the paper.

\section{References}

[1] BRAY F, RICHIARDI L, EKBOM A, PUKKALA E, CUNINKOVA $\mathrm{M}$ et al. Trends in testicular cancer incidence and mortality in 22 European countries: continuing increases in incidence and declines in mortality. Int J Cancer 2006; 118: 3099-3111. https://doi.org/10.1002/ijc.21747

[2] NIGAM M, ASCHEBROOK-KILFOY B, SHIKANOV S, EGGENER S. Increasing incidence of testicular cancer in the United States and Europe between 1992 and 2009. World J Urol 2015; 33: 623-631. https://doi.org/10.1007/s00345-0141361-y

[3] SIEGEL RL, MILLER KD, JEMAL A. Cancer statistics, 2019. CA Cancer J Clin 2019; 69: 7-34. https://doi.org/10.3322/ caac. 21551

[4] TIMP JF, BRAEKKAN SK, VERSTEEG HH, CANNEGIETER SC. Epidemiology of cancer-associated venous thrombosis. Blood 2013; 122: 1712-1723. https://doi.org/10.1182/ blood-2013-04-460121

[5] HISADA Y, MACKMAN N. Cancer-associated pathways and biomarkers of venous thrombosis. Blood 2017; 130: 1499-1506. https://doi.org/10.1182/blood-2017-03-743211

[6] PIKETTY AC, FLÉCHON A, LAPLANCHE A, NOUYRIGAT E, DROZ JP et al. The risk of thrombo-embolic events is increased in patients with germ-cell tumours and can be predicted by serum lactate dehydrogenase and body surface area. Br J Cancer 2005; 93: 909-914. https://doi. org/10.1038/sj.bjc.6602791

[7] LEVITAN N, DOWLATI A, REMICK SC, TAHSILDAR HI, SIVINSKI LD et al. Rates of initial and recurrent thromboembolic disease among patients with malignancy versus those without malignancy. Risk analysis using Medicare claims data. Medicine (Baltimore) 1999; 78: 285-291. https:// doi.org/10.1097/00005792-199909000-00001

[8] HONECKER F, KOYCHEV D, LUHMANN AD, LANGER F, DIECKMANN KP et al. Venous thromboembolic events in germ cell cancer patients undergoing platinum-based chemotherapy. Onkologie 2013; 36: 663-668. https://doi. org/10.1159/000355652

[9] BEZAN A, POSCH F, PLONER F, BAUERNHOFER T, PICHLER $M$ et al. Risk stratification for venous thromboembolism in patients with testicular germ cell tumors. PLoS One 2017; 12: e0176283. https://doi.org/10.1371/journal. pone. 0176283

[10] WEIJL NI, RUTTEN MF, ZWINDERMAN AH, KEIZER HJ, NOOY MA et al. Thromboembolic events during chemotherapy for germ cell cancer: a cohort study and review of the literature. J Clin Oncol 2000; 18: 2169-2178. https://doi. org/10.1200/jco.2000.18.10.2169 
[11] PAFFENHOLZ P, GREIN K, HEIDEGGER I, NESTLER T, GRABBERT $M$ et al. Predictors of thrombosis in testicular cancer during platinum-based chemotherapy. World J Urol 2019; 37: 1907-1916. https://doi.org/10.1007/s00345-0182598-7

[12] GIZZI M, OBERIC L, MASSARD C, POTERIE A, LE TEUFF $\mathrm{G}$ et al. Predicting and preventing thromboembolic events in patients receiving cisplatin-based chemotherapy for germ cell tumours. Eur J Cancer 2016; 69: 151-157. https://doi. org/10.1016/j.ejca.2016.10.003

[13] AKL EA, KAHALE LA, HAKOUM MB, MATAR CF, SPERATI $F$ et al. Parenteral anticoagulation in ambulatory patients with cancer. Cochrane Database Syst Rev 2017; 9: Cd006652. https://doi.org/10.1002/14651858.CD006652.pub5

[14] KHORANA AA, FRANCIS CW, CULAKOVA E, LYMAN GH. Risk factors for chemotherapy-associated venous thromboembolism in a prospective observational study. Cancer 2005; 104: 2822-2829. https://doi.org/10.1002/ cncr.21496

[15] LYMAN GH, KHORANA AA, FALANGA A, CLARKEPEARSON D, FLOWERS C et al. American Society of Clinical Oncology guideline: recommendations for venous thromboembolism prophylaxis and treatment in patients with cancer. J Clin Oncol 2007; 25: 5490-5505. https://doi. org/10.1200/jco.2007.14.1283

[16] NCSS 2019 Statistical Software. Kaysville, Utah, USA: NCSS, LLC; 2019.

[17] FIZAZI K, PAGLIARO L, LAPLANCHE A, FLECHON A, MARDIAK J et al. Personalised chemotherapy based on tumour marker decline in poor prognosis germ-cell tumours (GETUG 13): a phase 3, multicentre, randomised trial. Lancet Oncol 2014; 15: 1442-1450. https://doi.org/10.1016/ s1470-2045(14)70490-5
[18] FALANGA A, MARCHETTI M, VIGNOLI A. Coagulation and cancer: biological and clinical aspects. J Thromb Haemost 2013; 11: 223-233. https://doi.org/10.1111/jth.12075

[19] CANTWELL BM, MANNIX KA, ROBERTS JT, GHANI SE, HARRIS AL. Thromboembolic events during combination chemotherapy for germ cell-malignancy. Lancet 1988; 2: 1086-1087. https://doi.org/10.1016/s0140-6736(88)90113-4

[20] SRIKANTHAN A, TRAN B, BEAUSOLEIL M, JEWETT MA, HAMILTON RJ et al. Large retroperitoneal lymphadenopathy as a predictor of venous thromboembolism in patients with disseminated germ cell tumors treated with chemotherapy. J Clin Oncol 2015; 33: 582-587. https://doi. org/10.1200/jco.2014.58.6537

[21] MOORE RA, ADEL N, RIEDEL E, BHUTANI M, FELDMAN DR et al. High incidence of thromboembolic events in patients treated with cisplatin-based chemotherapy: a large retrospective analysis. J Clin Oncol 2011; 29: 3466-3473. https://doi.org/10.1200/jco.2011.35.5669

[22] SOLARI L, KRONIG M, IHORST G, DROGNITZ K, HEINZ J et al. High Rates of Thromboembolic Events in Patients with Germ Cell Cancer Undergoing Cisplatin-Based Polychemotherapy. Urol Int 2016; 96: 399-405. https://doi. org/10.1159/000445126

[23] ROBINSON AG, WEI X, KARIM S, RAPHAEL MJ, BEDARD PL et al. Venous Thromboembolism During Chemotherapy for Testicular Cancer: A Population-Based Study. Clin Oncol (R Coll Radiol) 2020; 32: e188-e193. https://doi. org/10.1016/j.clon.2020.03.013

[24] KEY NS, KHORANA AA, KUDERER NM, BOHLKE K, LEE AYY et al. Venous Thromboembolism Prophylaxis and Treatment in Patients with Cancer: ASCO Clinical Practice Guideline Update. J Clin Oncol 2019; 38: 496-520. https:// doi.org/10.1200/jco.19.01461 
https://doi.org/10.4149/neo_2021_210909N1295

\section{Low-molecular-weight heparin prophylaxis is not associated with decreased incidence of venous thromboembolism in testicular germ cell tumor patients receiving chemotherapy}

Nikola HAPAKOVA, Michal CHOVANEC, Katarina REJLEKOVA, Katarina KALAVSKA, Jana OBERTOVA, Patrik PALACKA, Valentina DE ANGELIS, Zuzana SYCOVA-MILA, Jozef MARDIAK, Michal MEGO*

\section{Supplementary Information}

Supplementary Table S1. Thrombosis location.

\begin{tabular}{ll}
\hline Inferior vena cava & 4 patients \\
Iliac vein & 4 patients \\
Popliteal vein & 3 patients \\
Subclavian vein & 1 patient \\
Iliofemoral vein & 1 patient \\
Pulmonary embolus & 1 patient \\
\hline
\end{tabular}

Supplementary Table S2. VTE events before and after 2010 based on IGCCCG risk group.

\begin{tabular}{lccccc}
\hline & $\begin{array}{c}\text { Patients without } \\
\text { prophylaxis } \\
\text { (before January 2010) }\end{array}$ & \multicolumn{2}{c}{$\begin{array}{c}\text { Patients with } \\
\text { prophylaxis }\end{array}$} & p-value \\
& $\mathrm{N}$ & $\%$ & $\mathrm{~N}$ & $\%$ & \\
\hline Stage IA/B & $0 / 17$ & 0.0 & $0 / 4$ & 0.0 & 1.0000 \\
Good & $4 / 84$ & 4.8 & $1 / 56$ & 1.8 & 0.6481 \\
Intermediate & $0 / 20$ & 0.0 & $1 / 14$ & 7.1 & 0.4118 \\
Poor & $3 / 46$ & 6.5 & $2 / 23$ & 8.7 & 1.0000 \\
Khorana score & & & & & \\
1 & $5 / 106$ & 4.7 & $1 / 57$ & 1.8 & 0.6659 \\
2 & $2 / 37$ & 5.4 & $1 / 19$ & 5.3 & 1.0000 \\
3 & $0 / 21$ & 0.0 & $2 / 20$ & 10.0 & 0.2317 \\
4 & $0 / 3$ & 0.0 & $0 / 1$ & 0.0 & 1.0000 \\
Size of retroperitoneal lymph nodes $(\mathrm{N}-\mathrm{stage})$ & & & \\
Normal (N0) & $1 / 43$ & 2.3 & $0 / 12$ & 0.0 & 1.0000 \\
$<2 \mathrm{~cm}(\mathrm{~N} 1)$ & $2 / 24$ & 8.3 & $1 / 6$ & 16.7 & 0.5235 \\
$>2 \mathrm{~cm}<5 \mathrm{~cm}(\mathrm{~N} 2)$ & $0 / 25$ & 0.0 & $0 / 30$ & 0.0 & 1.0000 \\
$>5 \mathrm{~cm}(\mathrm{~N} 3)$ & $3 / 64$ & 4.7 & $3 / 41$ & 7.3 & 0.6798 \\
\hline
\end{tabular}

Supplementary Table S3. Causes of treatment-related death.

\begin{tabular}{ll}
\hline Acute respiratory distress syndrome & 9 patients \\
Septic shock & 4 patients \\
Hemorrhagic shock & 1 patient \\
Pulmonary embolus & 1 patient \\
Bronchopneumonia & 1 patient \\
Sudden cardiac death (brain metastasis) & 1 patient \\
Unknown & 2 patients \\
\hline
\end{tabular}

